\title{
Çok Boyutlu Yoksulluk ile Ekonomik Büyüme İlişkisi: Türkiye ve Bazı Ülkeler İçin Sistem GMM Analizi (2010-2018) ${ }^{\mathrm{a}}$
}

\author{
Jiyan Kılıçç, c, Bedriye Tunçsiper ${ }^{d}$
}

\section{Özet}

Birleşmiş Milletler (BM) ve Oxford Yoksulluk ve İnsani Gelişme Girişimi (OPHI) iş birliği ile her yıl yayımlanan raporda yer alan Küresel Çok Boyutlu Yoksulluk Endeksi (ÇBYE), birçok gelişmekte olan ülkeyi kapsayan çok boyutlu yoksulluğun uluslararası bir ölçütüdür. ÇBYE, her ülkenin kendi içinde sahip olduğu koşullara göre uyarlanabilen ve temel olarak sağllk, eğitim ve yaşam koşulları boyutlarını barındıran fakat farklı boyutları da destekleyen bir yoksulluk ölçüsüdür. Bu çalışmada; 2010-2018 yılları arasında, Türkiye İstatistik Kurumu (TÜIK)'ndan talep edilen, 'Gelir ve Yaşam Koşulları Araştırması' mikro veri setleri kullanılarak, Türkiye için Çok Boyutlu Yoksulluk Endeksi tasarlanmıştır. Bahsi geçen endeks hesaplaması, AlkireFoster yöntemi (2011) kullanılarak oluşturulmuştur. Ayrıca, Türkiye ile BM ve OPHI'nin yayınladığı raporda yer alan bazı ülkelerin çok boyutlu yoksulluk endeksleri kullanılarak, çok boyutlu yoksulluk ve ekonomik büyüme arasındaki ilişkiyi ortaya koymak için Sistem GMM Tahmincisi ile test edilmesi amaçlanmıştır.
Anahtar Kelimeler

Çok Boyutlu Yoksulluk

Ekonomik Büyüme

Alkire-Foster Yöntemi

Sistem GMM Tahmincisi

Makale Hakkında

Geliş Tarihi: 28.06.2021

Kabul Tarihi: 15.12.2021

Doi: 10.18026/cbayarsos.958758

\section{The Relationship between Multidimensional Poverty and Economic Growth: System GMM Analysis for Turkey and Some Countries (2010-2018)}

\begin{abstract}
The Global Multidimensional Poverty Index (MPI), included in the annual report published by the United Nations (UN) and the Oxford Poverty and Human Development Initiative (OPHI), is an international measure of multidimensional poverty that covers many developing countries. The MPI is a measure of poverty that can be adapted to the conditions of each country and basically includes the dimensions of health, education and living conditions, but also supports different dimensions. In this study; between the years 20102018, requested from Turkey Statistical Institute (TSI) 'Income and Living Conditions Survey' using micro data sets, Multidimensional Poverty Index is designed for Turkey. The aforementioned index calculation was created using the Alkire-Foster method (2011). Additionally, some countries covered in the report issued by the UN and OPHI with Turkey using multidimensional poverty index, it is aimed to be tested with System GMM Estimator to reveal the relationship between multidimensional poverty and economic growth.
\end{abstract}

Keywords

Multidimensional Poverty

Economic Growth

Alkire-Foster Method

System GMM Estimator

About Article

Received: 28.06.2021

Accepted: 15.12.2021

Doi: 10.18026/cbayarsos. 958758

\footnotetext{
a Bu çalışma, 9-11 Nisan tarihlerinde Türkiye Ekonomi Kurumu tarafından gerçekleştirilen 7. Uluslararası Ekonomi Kongresi'nde (IceTea 2021) sunulan bildirinin genişletilmiş halidir.

b İletişim Yazarı: jikilic@gmail.com

c Doktora Öğrencisi, İzmir Demokrasi Üniversitesi, Sosyal Bilimler Enstitüsü, İktisat Bölümü, İzmir / Türkiye ve ORCID: 0000-0002-9904-8420

d Prof. Dr., İzmir Demokrasi Üniversitesi, İktisadi ve İdari Bilimler Fakültesi, İktisat Bölümü, İktisat Teorisi Anabilim Dalı, İzmir / Türkiye ve ORCID: 0000-0001-6063-218X,
} 


\section{Giriş}

Yoksulluk, kişinin temel gereksinimlere erişememe durumudur. Bunlar; yiyecek, içme suyu, barınma, sağlık ve temel eğitim gibi gereksinimlere sahip olamamak şeklinde sayılabilir. Günümüzde hem gelişmiş ülkeler hem de gelişmekte olan ülkelerde, özellikle gelir dağılımındaki eşitsizliğin artmasıyla da yoksulluk ile mücadele devam etmektedir. Fakat gelişmemiş ülkeler için ise bu durum günlük yaşamın bir parçası olmaktadır.

Çok boyutlu yoksulluk, kişinin gelir haricinde meydana gelen endeks bileşenlerinin oluşturduğu boyut ve göstergelerden yoksun olma durumudur. Küresel Çok Boyutlu Yoksulluk Endeksi (ÇBYE) 2020 raporuna göre, 1.3 milyar kişinin yaşadığ 107 gelişmekte olan ülkede nüfusun \% 22' sinin çok boyutlu yoksul olduğu tespit edilmiştir. Bu bakımdan çok boyutlu yoksulluk değerleri endeks kapsamında hesaplanması ve ülke ekonomilerinde yarattığı etkiler bakımından elde edilen sonuçların değerlendirilmesi son derece önemlidir.

$\mathrm{Bu}$ çalışmanın birinci bölümünde ÇBYE hakkında genel olarak bilgi verilerek, ekonomik büyüme ile olan ilişkisi açıklanmıştır. Akabinde, ÇBYE hesaplamasında kullanılan AlkireFoster yöntemi örnek bir çalışma ile detaylandırılmış ve Türkiye için hesaplanması planlanan ÇBYE boyut ve göstergeleri ikinci bölümde belirtilmiştir. Konu ile alakalı literatür taraması üçüncü bölümde yer verilmiştir. Çalışmaya ait veri, yöntem ve analiz sonuçları dördüncü bölümde açıklanmıştır. Son bölümde ise araştırma bulguları çerçevesinde değerlendirmeler ve politika önerilerinde bulunulmuştur.

\section{Çok Boyutlu Yoksulluk ve Ekonomik Büyüme İlişkisi}

Birleşmiş Milletler Kalkınma Programı'na (UNDP) ait Sürdürülebilir Kalkınma Hedefleri' nin (SKH) ilk amacı küresel çapta yoksulluğu ortadan kaldırmaktır. Bu kapsamda Küresel Çok Boyutlu Yoksulluk Endeksi; BM ve OPHI tarafından ortak bir şekilde gerçekleştirdikleri ve bu hedef doğrultusunda büyük katkı sağladığı çok boyutlu yoksulluğun uluslararası bir ölçüsüdür. Dolayısıyla ÇBYE; kimlerin ne kadar ve ne yoğunlukta yoksul olduğunu tespit etmek bakımından önem arz etmektedir. ÇBYE 2020 yılı raporuna göre, bu endeks 100'den fazla gelişmekte olan ülkeyi kapsayan bir endekstir.

ÇBYE kişilerin temel olarak sağlık, yaşam koşulları ve eğitim boyutlarından yoksun olma, bu imkanlara sahip olamama durumların inceler ve tespit eder. Endeks, bünyesinde mikro veri setlerini barındırmaktadır. Dolayısıyla, ülkelerin sahip olduğu çeşitli hane halkı anketleri doğrultusunda elde edilen bilgileri kapsamaktadır. OPHI' nin ÇBYE 3 boyut ve 10 göstergeden meydana gelmektedir. ÇBYE' ne göre bireyler, bu 3 boyutun üçte biri veya daha fazlasından yoksun olmaları durumunda çok boyutlu yoksul olarak kabul edilmektedir.

Her ülke sahip olduğu ekonomik şartlar ve yapısı gereği boyut ve göstergeleri normatif olarak belirleyebilmektedir. Diğer bir deyişle her ülke kendine özgü bir ÇBYE tasarlayabilmektedir. Dolayısıyla, Türkiye için ÇBYE tasarımı da bu çalışmanın ilk amacını oluşturmaktadır.

Yoksulluğun, ülkelerin sahip olduğu birçok makro ekonomik göstergeler üzerinde etkisi olduğu bilindiği gibi bu çalışmanın diğer amacı doğrultusunda sadece ekonomik büyüme ile ilişkisi üzerinde durulacaktır. Ülkelere ait ÇBYE 'nin yüksek bir skora sahip olması, söz konusu ülkenin mevcut ekonomik durumu açısından ciddi ve olumsuz bir tablonun ortaya çıkmasına neden olacaktır. Çünkü yoksulluk ile mücadelede alınacak tedbirler ülke GSYH'nı azaltacaktır. Bu bakımdan, çok boyutlu yoksulluğun hesaplanması neticesinde, ortaya çıkan 
yoksunluk durumları dikkate alındığında, ülke kaynaklarının verimli kullanımı ve bu kaynakların nereye kullanılması gerektiğinin tespit edilmesi açısından son derece önemlidir. Kaynak aktarımının doğru tespit edilmesi, kaynakların israf edilmesi önlenerek hem ekonomik büyümeye katkı sağlayacak hem de etkinliğin optimal bir şekilde gerçekleştirilmesini sağlayacaktır. Bu bakımdan yoksulluğun özellikle ekonomik büyüme üzerindeki etkisi önem teşkil etmektedir.

\section{Alkire - Foster Yöntemi}

Çok Boyutlu Yoksulluk Endeksi'nin hesaplanmasında kullanılan yöntem, Alkire ve Foster (Alkire ve Foster, 2011a) tarafından ortaya atılan AF Yöntemi' dir. AF Yöntemi; Foster, Greer ve Thorbecke (1984) tarafından öne sürülen tek boyutlu yoksulluk endeksinin ölçümünde kullanılan yöntemin devamı ve geliştirilmiş halidir. Bu yöntem, aksiyomlara dayalı çok boyutlu yoksulluk ölçütüdür. Aksiyomatik yöntemler belirleme seviyesinde sansürlenmiş kazanımlar yaklaşımı ve toplulaştırılmış kazanımlar yaklaşımı (Alkire, Robles ve Seth, 2015) olarak iki durumda incelenmektedir. Bu çerçevede AF Yöntemi; sansürlenmiş kazanımlar yaklaşım yöntemleri içinde en sık kullanılan sayma yaklaşımı kullanılarak yoksulluk ölçütü geliştiren bir yöntemdir (Karadağ, 2015, s.102-103).

Çalışmanın bu bölümünde, Alkire-Foster Yöntemi'ni (Alkire ve Foster, 2011b) daha detaylı anlatabilmek amacıyla bu çalışmanın yazarı tarafından belirlenen örnek üzerinden açıklanarak, çok boyutlu yoksulluk endeksinin nasıl hesaplandığı üzerinde durulmuştur.

Aşağıdaki Tablo 1'de X matrisinin toplam dört boyuttan oluştuğu ve dört kişiye ait bilgiler olduğu varsayılmaktadır. Her bir boyut eşit olarak ağırlıklandırılmıştır. Matrise ait boyut ve göstergeler ise şu şekildedir:

a. Kişinin 1 günlük dolar cinsinden kazanım durumunu veren gelir boyutu,

b. Kişinin tamamlamış olduğu eğitim yılını gösteren eğitim boyutu,

c. Kişinin kendi sağlığını 1'den 5'e kadar (1: kötü, 5: Çok iyi) değerlendirdiği sağlık boyutu

d. Kişinin çalışıp çalışmadığını gösteren istihdam boyutu

Tablo 1. Boyutlar

Gelir B. Eğitim B. Sağlık B. İstihdam B.

\begin{tabular}{|c|c|c|c|c|c|}
\hline & 13.1 & 14 & 5 & 1 & 1. Kİşİ \\
\hline$X=$ & 18.2 & $\underline{7}$ & 3 & $\underline{0}$ & 2. KİŞİ \\
\hline & $\underline{11.5}$ & $\underline{5}$ & $\underline{1}$ & $\underline{0}$ & 3. KIŞṠ \\
\hline & 21 & $\underline{11}$ & 4 & 1 & 4. Kİşi \\
\hline
\end{tabular}

$\mathbf{z}=13$

12

3

1

Yoksunluk Matrisi 
Z matrisi yoksunluk sınır matrisidir. Her bir boyutun aldığı değer, eğer yoksunluk sınırının altında kalırsa kişi o boyuttan yoksun olmaktadır ve "1" değerini almaktadır. Bu sınıra eşit veya sınırın üstünde bir değere sahip olur ise kişi o boyuttan yoksun olmamaktadır ve " 0 " değerini alır. Normatif olarak belirlenen yoksunluk sınırlarl; gelir, eğitim, sağlık ve istihdam boyutlarına göre sırasıyla 13, 12, 3 ve 1 olarak belirlenmiştir. $O$ halde; gelir boyutu için, 13 doların altında kalan kişiler gelir boyutundan yoksun olarak belirlenip, 1 değerini alırken, 13 dolara eşit ve üstünde kalan kişiler gelir boyutundan yoksun değil olarak tespit edilip, " 0 ” değerini alır. $X$ matrisi incelendiğinde sadece 3. kişi gelir yoksunudur. Eğitim boyutu incelendiğinde ise alınan eğitim yılı 12 senenin altında kalan kişiler eğitim boyutundan yoksun olarak tespit edilip 1 değerini alırken, 12 sene ve 12 senenin üstünde eğitim gören kişiler eğitim boyutundan yoksun değil olarak belirlenip, " 0 ” değerini almaktadır. $X$ matrisi incelendiğinde 2, 3 ve 4 . kişiler eğitim yoksunudur. Sağlık boyutu ele alındığında, kişinin kendi sağlık durumunu ifade etmek amacıyla verdiği puan 3'ün altında kalıyor ise kişi sağlık boyutundan yoksun olarak tespit edilip 1 değerini alır ve 3'e eşit veya 3'ün üstünde puana sahip olan kişiler ise sağlık boyutundan yoksun değil olarak ifade edilip " 0 " değerini almaktadır. X matrisi incelendiğinde sadece 3. kişi sağlık yoksunudur. Son olarak istihdam boyutu değerlendirildiğinde, bu göstergede “ 0 ” değeri kişinin çalışmadığını ifade etmektedir. $X$ matrisinde kişi 0 değerini alarak, 1 yoksunluk sınırının altında kaldığından istihdam boyutundan yoksun kabul edilip, 1 değerini almaktadır. Kişinin çalışması durumunda ise " 0 " değeri verilerek istihdam boyutundan yoksun olmadığ 1 tespit edilir. X matrisi incelendiğinde 2. ve 3. kişilerin istihdam yoksunu olduğu görülmektedir. Bu tespitler neticesinde aşağıdaki Tablo 2' de A ğırlıklı Yoksunluk Matrisi $\left(\mathrm{g}^{-0}\right)$ şu şekilde belirlenir:

Tablo 2. Ağırlık Yoksunluk Matrisi

$\begin{array}{cccccc}0 & 0 & 0 & 0 & \\ & & & & \\ \mathbf{g}^{0}=\mathbf{g}^{-0}= & 1 & 0 & 1 & \\ 1 & 1 & 1 & 1 \\ 0 & 1 & 0 & 0 & \mathbf{c}= & 4 \\ & & & & & \\ & & & & \end{array}$

Boyutlar eşit olarak ağırlıklandırıldığı için yoksunluk matrisi $\left(\mathrm{g}^{0}\right)$ ile ağırlık yoksunluk matrisi $\left(\mathrm{g}^{-0}\right)$ birbirine eşittir. Belirlenen yoksunluk sınırlarına $(\mathrm{z})$ eşit ve üstünde çıkması durumunda kişinin o boyuttan yoksun olmadığı sonucuna ulaşıldı. Sınırın altında kalan değerlerde kişi, o boyuttan yoksun olarak tespit edildi. İkili kesme yaklaşımı olarak da adlandırılan yöntem ile satır değerleri toplanarak her bir kişi için toplam yoksunluk skorlarını gösteren $c$ vektörü oluşturuldu. C vektörüne bakılarak, ikinci bir tip yoksulluk kısıtı (sınırı) belirlenir ve bu yoksulluk kısıtı k ile ifade edilir. Böylece, yoksulluk sınırı altında kimlerin fakir olduğu sorusuna yanıt bulunur. O halde, c vektöründen elde edilen yoksulluk kısıtı 2 (c vektörünün içindeki değer toplamının toplam kişi sayısına oranı) olduğuna karar verilerek, 2 ve 2'nin üstünde değere sahip olan kişiler yoksul olarak kabul edilir. Örnekte yer alan değerlere göre 
ise 2. ve 3. kişilerin yoksul olduğu tespit edildi. 2'nin altında kalan 1. ve 4. kişiler ise yoksulluk sınırının dişında kaldığına karar verilir.

Aşağıdaki Tablo 3' te görüldüğü üzere c vektöründe tespit edilen yoksullara göre belirlenen sansürlenmiş yoksunluk matrisine geçiş şu şekilde ifade edilir:

Tablo 3. Sansürlenmiş (Ağırlıklı) Yoksunluk Matrisi, (k=2)

$\mathbf{g}^{-0}(\mathbf{2})=\begin{array}{ccccc}0 & 0 & 0 & 0 & 0 \\ 0 & 1 & 0 & 1 & 2 \\ 1 & 1 & 1 & 1 & \mathbf{c}(2)=4 \\ 0 & 0 & 0 & 0 & 0\end{array}$

Dördüncü kişinin eğitim boyutundan yoksun olmasına rağmen, yoksulluk kesintisi $(k=2)$ altında yoksul olmadığı tespit edilmiştir. Bu durumu dikkate alarak; yoksul olmayan kişilerin maruz kaldığı yoksunlukları sıfırlamak amacıyla bir başka ifade ile bu kişileri sansürlemek amacıyla sansürlenmiş (ağırlıklı) matrisler elde edilir. Yoksulluk kısıtının 2 olduğu durumda sansürlü (ağırlıklı) yoksunluk matrisi g- ${ }^{0}$ (2) olarak oluşturuldu. Daha sonra yine satırlar toplanarak c(2) vektörü elde edilmektedir.

ÇBYE' nin elde edilişinde kullanılacak olan ilk ölçek “İnsan Sayısı Oranı” olarak ifade edilmektedir ve $\mathrm{H}$ ile gösterilen bu bileşen;

$$
\mathbf{H}=\frac{\text { Çok boyutlu fakir sayısı (c(2)vektöründeki kişi sayısı) }}{\text { Toplam Kişi Sayısı }}=\frac{2}{4}=\frac{1}{2}=0.5
$$

Elde edilen $\mathrm{H}^{\prime}$ ye göre her iki kişiden biri yoksuldur. ÇBYE' nin hesaplanmasında kullanılan ikinci ölçek bileşeni ise A ile ifade edilen "Yoksulluk Yoğunluğu" katsayısıdır. Yoksullar arasındaki yoksulluk payları hakkında bilgi sahibi olmamıza olanak sağlar. Yoksullar arasındaki yoksunluk payının ortalaması şeklinde de düşünülebilir.

Yoksullar arasındaki yoksunluk payı $\mathrm{c}(\mathrm{k}) / \mathrm{d}$ olarak bulunur. " $\mathrm{d}$ " matriste yer alan boyut sayısıdır. O halde;

2. kişi için; $c(2) / d=(2 / 4)=(1 / 2)$

3. kişi için; $c(2) / d=(4 / 4)=1$

olarak bulunur.

$\mathbf{A}=\frac{(1 / 2)+1}{2}=\frac{3}{2} * \frac{1}{2}=3 / 4=0.75$

$\mathrm{Bu}$ şekilde Yoksulluk Yoğunluğu katsayısı elde edilir. Yoksulluk Yoğunluğunun hesaplanmasında sansürlenmiş matris $\left(\mathrm{g}^{-0}(2)\right)$ dikkate alınır. Elde edilen A katsayısına göre yoksullar tüm yoksunlukların \% 75' ine maruz kalmaktadırlar. 
O halde, Sansürlenmiş Ağırlıklı Yoksunluk Matrisi $\left(\mathrm{g}^{-0}(2)\right)^{\prime}$ nin ortalaması alınarak Düzeltilmiş Yoksunluk Oranı Mo elde edilir.

$$
\mathbf{M}_{0}=\frac{\text { Yoksulların mahrum kaldığı ağırlıklı toplam boyut sayısı }}{\text { Herkesin tüm boyutlardan yoksun olması durumundaki toplam yoksunluk sayısı }}
$$

$$
\text { ya da }
$$

$$
\mathbf{M}_{0}=\mathbf{H}^{*} \mathbf{A}=(0.5) *(0.75)=0.375 \quad \text { şeklinde hesaplanır }
$$

OPHI ve BM' in her yıl yayımladığı raporda yer alan ve çalışmada kullanılacak olan diğer

\begin{tabular}{|c|c|}
\hline Boyut & Gösterge \\
\hline SAĞLIK & Yetersiz beslenme \\
\hline$(1 / 3)$ & 18 yaş altı çocuk ölüm sayısı \\
\hline \multirow{6}{*}{$\begin{array}{l}\text { YAŞAM } \\
\text { KOŞULLARI } \\
\quad(1 / 3)\end{array}$} & Elektriğe erişim \\
\hline & Oturulan konutun sahip olduğu zemin ve yapı özellikleri \\
\hline & Evin sanitasyon donanımı \\
\hline & $\begin{array}{c}\text { Hanenin aşağıdaki varlıklardan birden fazlasına sahip olma durumu: radyo, TV, } \\
\text { telefon, bilgisayar, hayvan arabası, bisiklet, motosiklet veya buzdolabı, araba veya } \\
\text { kamyon }\end{array}$ \\
\hline & Temiz içme suyuna erişim \\
\hline & Oturulan konutta yemek pişirmek amaciyla kullanılan temel yakıt türü \\
\hline \multirow{2}{*}{$\begin{array}{c}\text { EĞїTIM } \\
(1 / 3)\end{array}$} & Bitirilen okul yılının en az 6 yıl olma durumu \\
\hline & 8.sıfına kadar alması gereken eğitimi tamamlayamamış çocuğun olma durumu \\
\hline
\end{tabular}
ülkelere ait ÇBYE gösterge ve boyutları aşağıdaki Tablo 4' de gösterilmiştir.

Tablo 4. UNDP ve OPHI' nin ÇBYE Boyutları ve Göstergeleri

Kaynak: Alkire, Kanagaratnam ve Suppa, (2020)

OPHI' nin yayınladığı raporlarda Türkiye' nin yer almamasından dolayı Türkiye için bir Çok Boyutlu Yoksulluk Endeksi tasarlamak, bu araştırmanın ilk amacını oluşturmaktadır. Bu bölümün başında bahsedilen AF Yöntemi kullanılarak, 2010-2018 yılları için tasarlanan ÇBYE' nin boyut ve göstergeleri ise aşağıdaki Tablo $5^{\prime}$ te yer verilmiştir. 
Tablo 5. Türkiye İçin Tasarlanan ÇBYE ‘nin Boyutları ve Göstergeleri

\begin{tabular}{|c|c|c|}
\hline Boyut & Gösterge & $\begin{array}{l}\text { Yoksunluk } \\
\text { Eşiği }\end{array}$ \\
\hline \multirow{2}{*}{$\begin{array}{l}\text { SAĞLIK } \\
(1 / 3)\end{array}$} & $\begin{array}{l}\text { İstenildiği veya ihtiyaç duyulduğu zaman İKI GÜNDE BİR ET, } \\
\text { TAVUK YA DA BALIK İÇEREN YEMEK YİYİP YİYEMEME durumu } \\
\text { (Vejetaryenler için eşdeğer yiyecekler) }\end{array}$ & Yiyememe:1 \\
\hline & $\begin{array}{l}\text { Ferdin son } 12 \text { ay içinde, tıbbi muayene veya tedavi ihtiyacı olduğu } \\
\text { halde doktora başvuramama durumu }\end{array}$ & Hayırsa: 1 \\
\hline \multirow{6}{*}{$\begin{array}{l}\text { YAŞAM } \\
\text { KOŞULLARI } \\
(1 / 3)\end{array}$} & Ev / bina içinde TUVALET'in mevcut olma durumu & Hayırsa: 1 \\
\hline & $\begin{array}{l}\text { Oturulan konutta sızdıran çatı, nemli duvarlar, çürümüş pencere } \\
\text { çerçeveleri gibi bir problemin mevcut olma durumu }\end{array}$ & Evetse: 1 \\
\hline & $\begin{array}{l}\text { Ev / bina içinde BANYO veya DUŞ alma yerinin mevcut olma } \\
\text { durumu }\end{array}$ & Hayırsa: 1 \\
\hline & $\begin{array}{l}\text { Hane halkının CEP TELEFONU'na sahip olma durumu } \\
\text { Hane halkının RENKLİ TELEVİZYON'a sahip olma durumu } \\
\text { Hane halkının BİLGISAYAR'a sahip olma durumu } \\
\text { Hane halkının OTOMATIK ÇAMAŞIR MAKİNASI'na sahip olma } \\
\text { durumu } \\
\text { Hane halkının BUZDOLABI'na sahip olma durumu } \\
\text { Hane halkının BULAŞIK MAKİNASI'na sahip olma durumu } \\
\text { Hane halkının OTOMOBİL'e (iş amaçllar hariç) sahip olma durumu }\end{array}$ & $\begin{array}{l}\text { En az } 1 \\
\text { tanesi bile } \\
\text { yoksa: } 1\end{array}$ \\
\hline & Oturulan konutta BORULU SU SİSTEMİ'nin mevcut olma durumu & Hayırsa: 1 \\
\hline & $\begin{array}{l}\text { Oturulan konutta, konutun izolasyonundan dolayı 1sınma sorunu } \\
\text { olup olmadığı }\end{array}$ & Evetse: 1 \\
\hline \multirow{2}{*}{$\begin{array}{l}\text { EĞİTiM } \\
(1 / 3)\end{array}$} & En son bitirilen okul & $\begin{array}{l}\text { İlkokul } \\
\text { altiysa: } 1\end{array}$ \\
\hline & Okur yazarlık durumu & $\begin{array}{l}\text { Okur-Yazar } \\
\text { Değilse: } 1\end{array}$ \\
\hline
\end{tabular}

Kaynak: Yazar tarafından oluşturulmuştur.

Tablo $5^{\prime}$ te verilen göstergeler ve boyutlar çerçevesinde elde edilen sonuçlar her gösterge için belirlenen yoksunluk eşiği doğrultusunda kimlerin yoksul olduğuna karar verilmiştir. Bu çalışmada ise Türkiye için 2010-2018 yılları için TÜiK 'ten talep edilen, 'Gelir ve Yaşam Koşulları Araştırması' mikro veri setleri kullanılmıştır. Yapılacak olan analizde kullanılmak üzere Türkiye'nin Çok Boyutlu Yoksulluk Endeksi AF Yöntemi ile hesaplanmıştır. 


\section{Literatür Çalışmaları}

Aşağıda belirtilen çalışmalar dikkate alındığında hem bazı ülkelerin kendileri için tasarlamış olduğu ÇBYE çalışmalarına hem de çok boyutlu yoksulluğun etkilerinin incelendiği araştırmalara yer verilmiştir.

Santos, Dabus ve Delbianco (2019) çalışmalarında, 110 ülke için 1999-2014 yılları arasında ekonomik büyüme ve yoksulluk ilişkisini iki farklı yönteme göre ortaya koymayı amaçlamıştır. Yapılan Birinci Fark Tahmini Model sonuçlarına göre ekonomik büyümenin çok boyutlu yoksulluğu azalttığı belirlenmiştir. Fakat, bu etkinin bire bir ilişki içermesinin zayıf olduğu ve büyümenin gelir yoksulluğu üzerindeki etkisinden daha düşük olduğu sonucuna varılmıştır. Diğer yöntem olan Enine Kesit Modeline göre ulaşılan bulgular neticesinde yüksek ihracat seviyesine sahip ülkelerin, sanayi ve hizmetlerin yüksek paylarının ve yüksek seviyedeki yolsuzluk kontrolünün daha düşük çok boyutlu yoksulluğa sahip oldukları tespit edilmiştir.

Li ve diğerlerinin (2019), Çin için ilçe düzeyindeki nüfus sayımlarına dayanarak, 2000-2010 yılları arasında çok boyutlu yoksulluk endeksinin oluşumu için temel bileşenler analizi yapılmıştır. Çok boyutlu yoksulluğun Çin mekânsal ve zamansal olarak dağılımı, bir harita yardımı ile analiz edilmiştir. Çok boyutlu yoksulluğun ele alınan yıllar arasında nispeten azaldığı tespit edildiği ama bölgesel eşitsizliklerin devam ettiği bulgusuna ulaşılmıştır.

Öztornacı (2019)'nın doktora tez çalışmasında gerçekleştirmiş olduğu 2006-2016 yılları arasında toplam 4 boyut ve 17 gösterge ile Türkiye'nin ÇBYE değerleri hesaplanmıştır. Bu boyutlar; ekonomik durum ve varlıklar boyutu 7 gösterge, konut boyutu 5 gösterge, sağlık boyutu 3 gösterge ve istihdam boyutu 2 göstergeden oluşmaktadır. Türkiye'de çok boyutlu kırsal yoksulluk üzerinde etkili olan politikaların çok boyutlu yoksulluk üzerindeki etkileri 3 farklı ekonometrik yaklaşım ile analiz edilmiştir. Analiz sonuçlarına göre özel sosyal yardımların çok boyutlu yoksulluk üzerinde 3 yönteme göre de negatif ve istatistiksel olarak anlamlı etkisi olduğu tespit edilmiştir. Devlet yardımlarının etkisi ise yöntemlere göre farklılık göstermiştir. Elde edilen bulgular neticesinde, Türkiye'de çok boyutlu yoksulluk üzerinde en etkili değişkenler hane halkı büyüklüğü ve tarım sektöründe çalışmak olarak belirlenmiştir.

Abay ve Sezgin (2018) araştırmalarında; seçilmiş 8 AB üyesi ülke ve Türkiye için 2006-2015 yılları arasında eğitim, çalışan nüfus oranı, satın alma gücü paritesine göre milli gelir, enflasyon oranı ve net ücretin yoksulluk üzerindeki etkisi araştırılmıştır. Panel veri yöntemlerinden sabit etkiler modeli, tesadüfi etkiler modeli, havuzlanmış regresyon ve genelleştirilmiş momentler metodu ile test edilmiştir. Ulaşılan sonuçlara göre milli gelirin bütün modellerde ve eğitim değişkeninin ise sabit etkiler modeli haricindeki modellerde yoksulluğu azaltıcı yönde etki ettiği sonucuna varılmıştır. Enflasyon ve çalışan nüfus oranının ise yoksulluk üzerinde bir etkisi olmadığı belirlenmiştir.

Angulo ve diğerlerinin (2016) yaptıkları çalışmada, Alkire ve Foster metodolojisinden yararlanarak, 5 boyuttan oluşan (hane halkının eğitimi, çocukluk ve gençlik koşulları, sağlık, istihdam ve ev hizmetlerinde erişim ve yaşam koşulları) Kolombiya Çok Boyutlu Yoksulluk Endeksi tasarlamayı amaçlamışlardır. Elde edilen sonuçlara göre Kolombiya'da çok yönlülüğün hem kentsel hem de kırsal yoksulluk alanlarında 1997-2010 yılları arasında azaldığını ancak dengesizliklerin devam ettiği sonucuna ulaşılmıştır.

Karadağ ve Saraçoğlu (2015) çalışmalarında Türkiye için 2006-2012 yıllarını kapsayan iki farklı çok boyutlu yoksulluk ölçütü hesaplamışlardır. Elde edilen sonuçlar Türkiye ile Avrupa 
Birliği ülkeleri ile kıyaslanmıştır. Ulaşılan bulgular dahilinde Türkiye her ne kadar yoksulluk düzeyi bakımından $\mathrm{AB}$ ortalamasının altında kalmış olsa da 2012 yılına doğru ilerlediğinde önemli derecede düşüş gözlenmiştir.

Uğur (2015), TÜİK tarafından yayımlanan 2010 yılı Gelir ve Yaşam Koşulları Araştırması'nın mikro-kesit verilerinden yararlanarak Türkiye'nin sadece 2010 yıllı ÇBYE değerlerini hesaplamıştır. Yöntem olarak Alkire-Foster metodolojisinden yararlanılmıştır. Oluşturulan endeks içinde, eğitim ve sağlık boyutunda 2 gösterge, ekonomik durum ve varlıklar boyutunda 6 gösterge ve konut ve yaşam standardı boyutunda ise 6 gösterge olmak üzere toplamda 3 boyut ve 14 gösterge içermektedir. Ayrıca, bölgeler ve kent-kır ayrımı bakımından çok boyutlu yoksulluk değerleri ölçülmüştür.

Karadağ (2015) doktora tezi çalışmasında 2006-2012 yılları arasında Türkiye'ye özgü, temel tüketim boyutunda 4 gösterge, eğitim boyutunda 2 gösterge, sağlık boyutunda 3 gösterge, çalışma durumu boyutunda 3 gösterge ve konut koşulları boyutunda 4 gösterge ile Türkiye için, ÇBYE oluşturmuştur. Endeks hesaplamada Alkire-Foster (2011a) yöntemi kullanılmıştır. Elde edilen sonuçlar parasal yoksulluk göstergeleri ile karşılaştırılarak farklıkların ortaya konulması amaçlanmıştır.

Karaca ve Gökçek (2014), TR ile AB'ye aday olan geçiş ekonomilerinin insani gelişme ve çok boyutlu yoksulluk gibi sosyal ve ekonomik göstergelerle durumlarını karşılaştırmayı hedeflemişlerdir. TR'nin en yüksek çok boyutlu yoksulluk endeksine sahip ülke olduğu tespit edilmiştir.

Acar ve Başlevent (2014) Türkiye için ÇBYE oluşturmayı amaçlamışlardır. Tasarladıkları endeks 4 boyut ve toplam 15 göstergeden meydana gelmektedir. Bahsi geçen boyut ve gösterge dağılımları ise şu şekildedir: yaşam standardı boyutunda 7 gösterge, sağlık boyutunda 2 gösterge, konut boyutunda 4 gösterge ve işgücü piyasası durumu boyutunda 2 gösterge yer almaktadır. Türkiye için hesaplanan ÇBYE 2007-2010 yıllarını kapsamakta olup, çalışmada eğitim boyutuna yer verilmemiştir.

\section{Veri, Yöntem ve Analiz}

BM ve OPHI' nin yayımladığı raporda yer alan bazı ülkeler ile yazar tarafından hesaplanan Türkiye için Çok Boyutlu Yoksulluk Endeksi kullanılarak, çok boyutlu yoksulluk ve ekonomik büyüme arasındaki ilişkiyi tespit etmek amaçlanmıştır. Bu amaç doğrultusunda; çalışmada 61 ülke için yıllık veriler kullanılmış olup incelenen dönem aralığ $2010-2018$ yıllarıdır.

Çalışmanın Türkiye'ye ait veri seti TÜİK' ten talep edilen 2010 - 2018 yılları arasındaki “Gelir ve Yaşam Koşulları Araştırması' mikro veri setinden elde edilmiştir. Bahsi geçen diğer ülkeler ele alınırken zaman kısıtı altında en çok veri setine ulaşılan 60 ülke tercih edilmiştir. Bu ülkeler; Bangladeş, Belize, Benin, Bolivya, Burkina Faso, Burundi, Kamboçya, Kamerun, Kolombiya, Kongo-DR, Fildişi Sahili, Dominik Cumhuriyeti, Mısır, Etiyopya, Gambiya, Gana, Gine, Guyana, Haiti, Honduras, Hindistan, Endonezya, Irak, Ürdün, Kenya, Lao, Lesotho, Liberya, Madagaskar, Malavi, Mali, Moritanya, Meksika, Moldova, Moğolistan, Karadağ, Mozambik, Namibya, Nepal, Nikaragua, Nijer, Nijerya, Pakistan, Peru, Filipinler, Ruanda, Sao Tome ve Principe, Senegal, Sierra Leone, Surinam, Tacikistan, Tanzanya, Tayland, Togo, Trinidad ve Tobago, Ukrayna, Özbekistan, Vietnam, Zambiya ve Zimbabve'dir. Bunun yanında oluşturulacak olan panel veri seti; OPHI tarafından yayımlanan raporlarda 2012 yılına ait veri 
setinin olmamasından dolayı analiz dengesiz panel olarak gerçekleştirilmiştir. Bahsi geçen tüm ülkelere ait ekonomik büyüme rakamları ise GSYİH büyümesi (yıllık \%) olarak ele alınmıştır ve veriler Dünya Bankası'ndan temin edilmiştir. Analizde GSYH büyümesi "gdp" olarak sembolize edilirken, ülkelere ait Çok Boyutlu Yoksulluk Endeksi ise "mpi" olarak gösterilmiştir.

AF Yöntemi ile belirlenen ÇBYE ve ekonomik büyüme ilişkisini ortaya koymak amacıyla, Dinamik Panel Veri Model tahmin yöntemlerinden olan Sistem Genelleştirilmiş Momentler Tahmincisi (Sistem GMM) ile analizin gerçekleştirilmesine karar verilmiştir. Bahsi geçen analiz, Stata-14 ekonometrik analiz paket programı kullanılarak gerçekleştirilmiştir.

\section{Sistem Genelleştirilmiş Momentler Tahmincisi (Sistem GMM)}

Modelde T(zaman) boyutu küçük olduğunda, bağımlı değişkenin gecikmeleri varsa, bağımlı değişkene ait gecikme parametresi FE (Fixed Effect-Sabit Etki) ve RE (Random Effect-Rassal Etki) ile tahmin edilmek istenildiğinde sapmalı sonuçlar elde edilir. Literatürde bu sapma; “Nickell sapması" Nickell (1981) olarak söz edilmektedir. Bu durumda; parametreler sapmalı ve tutarsız sonuçlar verir. T boyutu arttıkça Nickell sapması da ortadan kalkar. Dolayısıyla; FE ve RE tahmincileri yerine Dinamik Panel Veri Model tahminlerinden olan GMM tahmincisinin kullanılmasına karar verilmiştir. Genel olarak dinamik panel veri modeli şu şekilde ifade edilebilir:

$$
\operatorname{Gdp}_{i t}=\alpha \operatorname{Gdp}_{i t-1}+\beta \mathrm{Mpi}_{\mathrm{it}}+\mu_{\mathrm{i}}+\mu_{\mathrm{it}}
$$

Gecikme paremetresinin, T'nin küçük olduğu durumlarda tahmin edilememe problemini çözmek amacıyla Birinci Farklar (Difference) ve Sistem GMM tahmincisi olmak üzere 2 çeşit GMM önerilmektedir. Farklara dayanarak yapılan GMM, Birinci Farklar GMM olarak adlandırılmaktadır. Arellano ve Bond, Birinci Farklar tahmincisi üzerinden araç değişken tanımlayarak bu modeli kurarken, Blundell ve Bond (1998) ise bir adım daha ileriye giderek düzeyde, farkı alınmamış denkleme de araç değişken ekleyerek Sistem GMM tahmincisini geliştirmiştir. Elde edilen GMM tahminci sonuçları incelenirken iki önemli kritere dikkat edilmelidir. Bu iki test kurulan GMM modelin geçerliliğini doğrular. Bu testler; Arellano-Bond ve Araç Değişkenlerin Geçerliliği Testidir.

\section{Arellano-Bond Testi:}

$\mathrm{AR}(1)$ ve $\mathrm{AR}(2)$ otokorelasyon testleridir. GMM tahmincisinin etkin olması için ikinci mertebeden otokorelasyonun olmaması gerekmektedir. Bu yüzden bu testin yapılması son derece önem arz etmektedir. Birinci mertebe otokorelasyonun olmaması çok sık aranmaz ve birinci mertebe otokorelasyonun negatif olması beklenirken, ikinci mertebeden otokorelasyonun kesinlikle olmaması gerekmektedir.
a. AR (1) Testi için:
Ho: Otokorelasyon yoktur.
$\mathrm{H}_{1}$ : Otokorelasyon vardir.

Hipotezleri kurulur ve " olasılık değeri < 0,05 " olması istenir. (Ho: reddedilir, H1: kabul edilir) 
b. AR (2) Testi için: Ho: Otokorelasyon yoktur.

$\mathrm{H}_{1}$ : Otokorelasyon vardır.

Hipotezleri kurulur ve "olasılık değeri $>0.05$ " olması istenir. $\left(\mathrm{H}_{0}\right.$ : kabul edilir, $\mathrm{H}_{1}$ : reddedilir)

\section{Araç Değişkenlerin Geçerliliği Testi:}

Araç değişkenlerin geçerli olup olmadığına, Hansen ve Sargan testleri sonucunda karar verilir. Sargan testi yardımıyla, aşırı tanımlama kısıtlamalarının yani araç değişkenlerin geçerliliği test edilmektedir. Her iki test içinde hipotezler aynı olup "olasılık değeri $>0.05$ " olması istenir ( $\mathrm{H}_{0}$ : kabul edilir, $\mathrm{H}_{1}$ : reddedilir). Aksi durumda modelin kurulumu için araç değişkenler yetersiz kalacaktır.

Ho: Araç değişkenler geçerlidir. Aşırı tanımlama kısıtlamaları geçerlidir.

$\mathbf{H}_{1}$ : Araç değişkenler geçerli değildir. Aşırı tanımlama kısıtlamaları geçerli değildir.

Çalışılan veri setinin $\mathrm{T}=9$ ve $\mathrm{N}=61(\mathrm{~T}<\mathrm{N})$ olması ve dengesiz panel veri setine sahip olunmasından dolayı farkları alınarak yapılan Birinci Fark GMM tahmincisi, gözlem sayısının azalmasına neden olacaktır. Bu nedenle dengesiz panel ve T'nin küçük, N'nin büyük olduğu veri setine olanak tanıyan Arellano ve Bover/Blundell ve Bond birinci farklar yerine ileri ortogonal sapmaları önerdiği Sistem GMM tahmincisi ile aşağıdaki sonuçlar elde edilmiştir (Tatoğlu, 2018, s.152):

Tablo 6: Arellano ve Bover/Blundell ve Bond'un İki Aşamalı Sistem GMM Tahmin Sonuçları

\begin{tabular}{|c|c|c|c|}
\hline Açıklayıcı Değişkenler & Katsayılar & Düzeltilmiş Standart Hatalar & Olasılık Değeri \\
\hline Ln_Gdpi,t-1 Katsay1s1: & .4771062 & .1123107 & $4.25(0.000)^{*}$ \\
\hline Ln_Mpi & -.2341819 & .0527383 & $-4.44(0.000) *$ \\
\hline Arellano-Bond Testi: AR(1) & & & $-3.30(0.001) *$ \\
\hline Arellano-Bond Testi: AR(2) & & & $-2.08(0.037) *$ \\
\hline Sargan Testi & & & $25.83(0.001)^{*}$ \\
\hline Hansen Testi & & & $10.96(0.140)$ \\
\hline Fark Hansen GMM & & Chi2 (6) & $10.69(0.098)$ \\
\hline (Düzeyde araç değişkenler için) & & Chi2 (1) & $0.26(0.608)$ \\
\hline Fark Hansen GMM & & Chi2 (6) & $7.90(0.246)$ \\
\hline iv(lnmpi) & & Chi2 (1) & $3.06(0.080)$ \\
\hline Araç Değişken Sayısı: 9 & & Grup Sayısı: 61 & \\
\hline
\end{tabular}

Not: $\left(^{*}\right) \% 5$ anlamlllık düzeyini ifade etmektedir. 
Yukarıdaki Tablo 6' da dirençli standart hataları tespit etmek amacıyla Windmeijer (2005)'in küçük örnek düzeltmesi kullanılarak elde edilen Arellano ve Bover/Blundell ve Bond'un İki Aşamalı Sistem GMM tahmin sonuçlarına yer verilmektedir. Bağımlı değişken olarak kabul edilen gdp katsayısının 1 gecikmeli değeri modele dahil edildiği görülmektedir. Hem gdp'nin bir gecikmeli değeri hem de mpi değişkenine ait $\mathrm{z}$ olasılık değerleri $(\mathrm{p}>\mathrm{z}) 0.05$ anlamlılık seviyesinden küçük olarak tespit edilmiştir ve anlamlı sonuçlara ulaşılmıştır. Windmeijer'in dirençli standart hataları ile hesaplanan $\mathrm{z}$ test istatistiğine göre, gecikmeli değişken ve çok boyutlu yoksulluk endeksindeki değişim, gdp'deki değişmeyi açılamakta anlamlıdır. GMM' in etkinliği araç değişken sayısı bakımından değerlendirildiğinde, araç değişken sayısı, grup sayısını aşmamıştır. Modelde 9 tane araç değişken kullanılmıştır.

GMM tahmincisinde Arellano - Bond Test sonuçlarına bakıldı̆̆ında birinci mertebeden otokorelasyonun negatiflik durumu tespit edilmiştir fakat $\% 5$ anlamlılık düzeyinde 1.mertebe otokorelasyonun varlığı söz konusudur. AR (2) test sonuçları incelendiğinde ise z olasılık değeri (0.037) 0,05'ten küçük çıkmış fakat 0,01 anlamlılık seviyesinden büyük olarak tespit edilmiştir. Dolayısıyla, 0,05 anlamlılık düzeyinde $\mathrm{H}_{0}$ hipotezi reddedilirken, 0,01 anlamlılık seviyesinde $\mathrm{H}_{1}$ hipotezi reddedilmiştir.

Sargan ve Hansen test sonuçlarına göre modele dahil edilen araç değişkenlerin sayısının yeterlik durumu tespit edilir. Sargan test sonuçlarına göre olasılık değeri 0,05'ten küçük çıkarak sağlam olmayan araç değişken sonuçları elde edilmiştir. Öte yandan Hansen test sonuçları incelendiğinde Chi2 olasılık değeri (0.140), 0,05'ten büyük çıkmıştır ve $\mathrm{H}_{1}$ hipotezi reddedilmiştir. Modelde araç değişkenler aşırı olarak belirlenmiştir ve geçerliliğini devam ettirmektedir. Son olarak; araç değişkenlerin dışsallık durumu Fark Hansen Test sonuçları ile karar verilir. Elde edilen test sonuçları incelendiğinde, her iki moment koşulu içinde Chi2 olasılık değerleri, 0,05'ten büyük çımıştır ve $\mathrm{H}_{0}$ hipotezi kabul edilerek araç değişkenlerin dişsal olduğu sonucuna ulaşılmıştır.

\section{Sonuç}

$\mathrm{Bu}$ çalışma, çok boyutlu yoksulluk ve ekonomik büyüme arasındaki ilişkiyi test etmek amacıyla yapılmıştır. Ele alınan 61 ülke için ekonomik büyüme ve Çok Boyutlu Yoksulluk Endeksi değişkenleri 2010-2018 yılları arasında incelenmiştir. Türkiye için ÇBYE değerleri veri eksikliği nedeniyle, OPHI tarafından hesaplanmadığ için bu çalışmada yeni bir 3 boyutlu ÇBYE tasarlanmıştır. Türkiye için hesaplanan ÇBYE verilerini de dikkate alarak, bahsi geçen diğer ülkeler ile panel analiz gerçekleştirilmiştir. Modelin, veri eksikliği ve zaman kısıtından dolayı dengesiz panel olarak kurulmasına karar verilmiştir. Böylelikle, dinamik panel veri modeli kurulmuştur ve sistem GMM tahmincisi ile test edilmiştir. Tahminciye ait sonuçlar incelendiğinde, birinci mertebe otokorelasyonun negatiflik durumu tespit edilmiştir. ikinci mertebe otokorelasyon bulgularının değerlendirilmesi bakımından Arellano-Bond Testi uygulanmıştır ve 0,01 anlamlılık seviyesinde otokorelasyonun olmadığ Modelde kullanılan araç değişkenlerin geçerli ve aşırı belirlenmiş olma durumunu test eden Hansen test sonuçlarına göre de araç değişkenlerin dışsal olduğu belirlenmiştir. Elde edilen bulgular neticesinde çok boyutlu yoksulluk ile ekonomik büyüme arasında negatif bir ilişki olduğu sonucuna ulaşılmıştır.

Yapılan çalışmadan elde edilen bulgular doğrultusunda, çok boyutlu yoksulluğun azaltılmasının ekonomik büyüme üzerinde yarattığı olumlu katkı düşüncesini de 
desteklemektedir. Dolayısıyla ekonomik büyüme için yoksulluk ile mücadele önemli bir rol oynamaktadır. ÇBYE kapsamında hesaplanan göstergeler ve boyutlar dikkate alındığında, yoksulluğu azaltmak için alınacak önlemler ve politikaların etkinliği, kaynak israfına yol açmadan kaynakların verimli kullanılmasına olanak sağlayacaktır. Ülkelerin sahip olduğu yoksunluk boyutları çerçevesinde spesifik yatırımların ve desteklemelerin gerçekleşmesine fırsat vermektedir. Bu bakımdan her ülke sahip olduğu yoksunluk boyutları çerçevesinde detaylı tespitler yapmalı ve öngörülebilir kararlar almalıdır. Böylelikle hem kaynak tahsisinin nereye yapıldığı hem de nasıl etkiler sağladığının takibi ve tespiti bakımından da kolaylık sağlayacaktır.

Dünya ekonomisinin içinde bulunduğu COVID-19 salgınının yarattığı pandemi ortamı yoksullukla mücadele eden birçok ülkeyi normalden daha fazla zor duruma sokmuştur. Halı hazırda zaten sağlık yoksunluğu çeken yoksulların, bu süreç boyunca yaşadıkları problemler daha ağır bir şekilde hissedilmiştir. Daha da ötesi, pandemi boyunca insanların var olan işlerini de kaybetmeleri gibi birçok ekonomik sıkıntıyla karşı karşıya kalmaları, kişilerin dolaylı olarak diğer boyutlardaki yoksunluk durumlarını da tetikleyecektir. Bu kapsamda bu çalışmanın zaman kısıtından dolayı pandemi sürecinin etkisi ele alınamamıştır. Fakat ileride yapılacak olan araştırmaların, elde edilecek veriler doğrultusunda çok boyutlu yoksulluk ve ekonomik büyüme kapsamında pandemi sürecinin etkileri, değerlendirilmesi ve araştırma sonuçlarının tespitleri bakımından literatüre katkı sağlayacağı düşünülmektedir.

\section{Kaynakça}

Abay, Ç. \& Sezgin, S. (2018). Türkiye ve Bazı AB Ülkelerinde Yoksulluk ve Gelir Dağılımı. Journal of Life Economics, Cilt: 5, Say1: 4, s. 97-110.

Acar, A. \& Başlevent, C. (2014). Examinatin of The Transition of Households Into And Out of Poverty in Turkey. Betam Working Paper Series, 15.

Alkire, S. \& Foster, J. E. (2011b). Understandings And Misunderstandings of Multidimensional Poverty Measurement. Journal of Economic Inequality, 9(2), 289-314.

Alkire, S. \& Foster, J. E. (2011a). Counting And Multidimensional Poverty Measurement. Journal of Public Economics, vol. 95(7-8), ss: 476-487.

Alkire, S. \& Robles, G. (2015). Multidimensional Poverty Index 2015: Brief Methodological Note And Results. Oxford Poverty and Human Development Initiative, University of Oxford, Briefing 31, (2015 ÇBYE verileri).

Alkire, S. \& Santos, M.E. (2010). Acute Multidimensional Poverty: A New Index For Developing Countries. OPHI Working Paper 38. (2010 ÇBYE verileri)

Alkire, S., A. Conconi, \& S. Seth (2014). Multidimensional Poverty Index 2014: Brief Methodological Note And Results. Oxford Poverty and Human Development Initiative, Oxford University. ophi.qeh.ox.ac.uk (2014 ÇBYE verileri).

Alkire, S., A. Conconi, \& J.M. Roche (2013). Multidimensional Poverty Index 2013: Brief Methodological Note And Results. Oxford Poverty and Human Development Initiative, Oxford University. ophi.qeh.ox.ac.uk (2013 ÇBYE verileri)

Alkire, S., \& Robles, G. (2016). Multidimensional Poverty Index Winter 2016: Brief Methodological Note And Results. Oxford Poverty and Human Development Initiative, University of Oxford, OPHI Briefing 44. (2016 ÇBYE verileri).

Alkire, S., \& Robles, G. (2017). Multidimensional Poverty Index Summer 2017: Brief Methodological Note And Results. Oxford Poverty and Human Development Initiative, University of Oxford, OPHI Methodological Notes 45. (2017 ÇBYE verileri). 
Alkire, S., Conconi, A., Robles, G. \& Seth, S. (2015). Multidimensional Poverty Index, Winter 2014/2015: Brief Methodological Note And Results. OPHI Briefing 27, University of Oxford, Ocak, (2015 ÇBYE verileri).

Alkire, S., Jindra, C., Robles, G. \& Vaz, A. (2016). Multidimensional Poverty Index 2016: Brief Methodological Note And Results. Oxford Poverty and Human Development Initiative, University of Oxford, OPHI Briefing 42. (2016 ÇBYE verileri).

Alkire, S., Kanagaratnam, U. \& Suppa, N. (2018). The Global Multidimensional Poverty Index (MPI): 2018 Revision. OPHI MPI Methodological Notes 46, Oxford Poverty and Human Development Initiative, University of Oxford. (2018 ÇBYE verileri).

Alkire, S., Kanagaratnam, U. \& Suppa, N. (2020). The Global Multidimensional Poverty Index (MPI) 2020. OPHI MPI Methodological Note 49, Oxford Poverty and Human Development Initiative, University of Oxford.

Alkire, S., Roche, J.M. Santos, M.E. \& Seth, S. (2011). Multidimensional Poverty Index 2011: Brief Methodological Note. The Oxford Poverty and Human Development Initiative (OPHI), Oxford Department of International Development Queen Elizabeth House, University of Oxford, 4 Kasım, (2011 ÇBYE verileri).

Angulo, R., Diaz, Y. \& Pardo, R. (2016). The Colombian Multidimensional Poverty Index: Measuring Poverty In A Public Policy Context. Soc Indic Res 127, s. 1-38, DOI 10.1007/s11205015-0964-Z

Blundell, R. \& Bond, S. (1998). Initial Conditions And Moment Restrictions in Dynamic Panel Data Models. Journal of Econometrics, 87, s. 115-143.

Foster, J. E., Greer, J. \& Thorbecke, E. (1984). A Class Of Decomposable Poverty Indices. Econometrica, February, 52(3), ss:(761-66) DOI: 10.2307/1913475

Karaca, N. G. \& Gökçek, B. (2014). Türkiye ve Geçiş Ekonomilerinde Çok Boyutlu Yoksulluk ve İnsani Gelişme. International Conference On Eurasian Economies.

Karadağ, M. A. (2015). Tek Boyutlu ve Çok Boyutlu Yoksulluk Ölçümleri: Türkiye Uygulaması. (Doktora Tezi, Gazi Üniversitesi).

Karadağ, M. A. \& Saraçoğlu, B. (2015). Çok Boyutlu Yoksulluk Analizi: Türkiye-AB Karşılaştırması. Amme İdaresi Dergisi, Cilt 48, Sayı 4, Aralık, s.129-159.

Li, G., Cai, Z., Liu, J., Liu, X., Su, S., Huang, X. \& Li, B. (2019). Multidimensional Poverty in Rural China: Indicators, Spatiotemporal Patterns And Applications. Springer, Social Indicators Research 144, s. 1099-1134, https://doi.org/10.1007/s11205-019-02072-5

Nickell, S. (1981). Biases in Dynamic Models With Fixed Effects. Ekonometrik, Cilt 49, No.6 (Kasım 1981) , s. 1417-1426.

Öztornacı, B. (2019). Türkiye'de Çok Boyutlu Kırsal Yoksulluk ve Belirleyenleri. (Doktora Tezi, Çukurova Üniversitesi, Fen Bilimleri Enstitüsü).

Santos, M. E., Dabus, C. \& Delbianco, F. (2019). Growth And Poverty Revisited From A Multidimensional Perspective. The Journal of Development Studies, 55:2, s. 260-277, DOI: 10.1080/00220388.2017.1393520

Tatoğlu, F.Y. (2018). İleri Panel Veri Analizi-Stata Uygulamalı. Beta Basım Yayım Dağıtım A.Ş., 3.Bask1, İstanbul.

Türkiye İstatistik Kurumu (TÜIK). Gelir ve Yaşam Koşulları Araştırması. Mikro veri seti, (2010-2018) Uğur, M.S. (2015). Yoksulluğun Çok Boyutluluğu ve Türkiye İçin Çok Boyutlu Bir Yoksulluk Ölçümü. EY International Congress on Economics II, "Growth, Inequality and Poverty".

Windmeijer, F. (2005). A Finite Sample Correction For The Variance of Linear Efficient Two-Step GMM Estimators. Journal of Econometrics, 2005, vol. 126, Say1 1, s. 25-51.

World Bank. World Development Indicators. Washington DC, Erişim Tarihi: 17/02/2021, https://data.worldbank.org/ 